\title{
Women's Healthcare Decision-Making Autonomy by Wealth Quintile from Demographic and Health Surveys (DHS) in Sub-Saharan African Countries
}

\author{
Lee Rose*, Kumar Jessica, and Al-Nimr Amer \\ Combined Medicine-Pediatrics Infectious Disease Fellow, Beth Israel Deaconess Medical Center, Boston Children's \\ Hospital, USA
}

*Corresponding author: Rose Lee, Combined Medicine-Pediatrics Infectious Disease Fellow, Beth Israel Deaconess Medical Center, Boston Children's Hospital, Boston, USA, E-mail: rlee7@bidmc.harvard.edu

\section{Introduction}

The UN Millennium Declaration in September 2000 was a milestone in history that marked a commitment of world leaders to a global partnership of time-bound targets for 2015 that became known as the Millennium Development Goals (MDG). MDG3 to promote gender equality and empower women included targets to eliminate gender disparities in the realms of education, employment, and government. Whereas goals such as MDG1 on poverty reduction reached its target ahead of schedule, gender gaps remain significant worldwide. One-third of countries in developing regions have not yet achieved gender parity in primary education, and as of 2015 approximately 50\% of all working-age women are in the labor force compared to $77 \%$ of men [1].

The relationships between women empowerment, economic development, and favorable health outcomes are too extensive to capture in a simple causal diagram. Economists have described a "virtuous cycle" between women empowerment and development, and the need for sustained policy commitment to gender equality from both moral imperative and pragmatic need [2]. A substantial body of literature already connects women's empowerment with positive outcomes for women, families, and society. Economies grow when women work and an increase in female labor force participation results in faster economic growth [3]. The inferior social status of women in many cultures negatively impacts healthcare outcomes for women and children $[4,5]$.
Gender based discrimination has resulted in significant female morbidity and mortality around the world and was popularized with Amartya Sen's concept of "missing women" in 1992 with estimates of greater than 100 million missing women worldwide at the time [6] and larger estimates nearly a decade later [7].

In 2008, the United Nations Development Programme (UNDP) developed a Gender Inequality Index (GII) [8], which is a composite measure of women's reproductive health, empowerment, and labor participation. An ecological study found an association between this index and neonatal, infant, and under-five mortality rates even after adjustment for confounders such as a per capita gross domestic product and immunization coverage [9]. A systematic review of 219 countries showed that for every additional year of formal education for women child mortality decreased by $9.5 \%$ [10]. Studies across multiple countries with high levels of gender discrimination showed that female autonomy and higher social status is associated with improved family planning and perinatal care utilization [11-16] and lower rates of infant and child mortality $[9,11,17-$ 19].

Families in which women have decision-making roles devote a greater share of family resources to the children [20-22]. Evidence from a panel of countries has similarly demonstrated that when women have a greater share of household income from cash transfers or through labor force participation, more family spending

Citation: Lee R, Kumar J, Al-Nimr A (2017) Women's Healthcare Decision-Making Autonomy by Wealth Quintile from Demographic and Health Surveys (DHS) in Sub-Saharan African Countries. Int J Womens Health Wellness 3:054. doi.org/10.23937/2474-1353/1510054

Received: September 06, 2016: Accepted: June 02, 2017: Published: June 05, 2017

Copyright: (c) 2017 Lee R, et al. This is an open-access article distributed under the terms of the Creative Commons Attribution License, which permits unrestricted use, distribution, and reproduction in any medium, provided the original author and source are credited.

CLINMED INTERNATIONAL LIBRARYC 
is for the benefit of children [23]. A Dominican Republic study found that children were significantly less stunted in female-headed vs. male-headed households [24].

The definition of female autonomy has increasingly moved towards an understanding as a multidimensional phenomenon with separate elements possessive of independent effects. As such, some discourage the use of a single index to represent autonomy and advocate for the investigation of the individual dimensions of autonomy [25]. Women's autonomy in healthcare decision-making was included in national questionnaires conducted by the Demographic and Health Surveys conducted in the 2000's in Low and Middle Income Countries (LMIC). Women living in LMIC experience significantly more gender equality than those in high income countries [9], and these same areas of the world have the most to gain in terms of economic development and women's empowerment.

Research into female healthcare decision-making autonomy is an area of growing interest due to its importance from both a human rights and healthcare outcomes perspective. Data has shown that urban and wealthier women in many LMIC tended to deliver in medical settings with the assistance of a skilled health worker [26]. However, it is unclear how socioeconomic status contributes to women's healthcare decision-making behaviors. The nature of this question is complex and likely bidirectional. Prior data has shown that women with paid employment have increased household decision-making autonomy although this relationship has not been specifically queried with regards to healthcare choices $[27,28]$. There are many pathways by which female healthcare autonomy could be causal or correlated with higher socioeconomic status. Women with decision-making power over their health and utilize services maybe more fit to work contributing to higher familial income. Conversely, wealth and its association with urbanicity, higher education, and distinct cultural norms among many other factors are all possible confounders in the relationship between wealth and healthcare decision-making. Nonetheless as cash transfer programs have become popularized in the international development community as a social protection instrument, a better understanding of the relationship between wealth and female healthcare autonomy seems increasingly relevant. These interventions have demonstrated positive effects on the health and well-being of children and families [29], and possibly these effects may be partially mediated through increased female healthcare autonomy. This study aims to address if women residing in low and middle income countries who are in higher wealth quintiles have more autonomy over decisions regarding their own healthcare compared to women in lower wealth quintiles.

\section{Methods}

This study is a comparative cross-sectional analysis of de-identified data from the Demographic and Health Surveys (DHS). We requested permission to use these publicly available datasets from The DHS Program. The six sub-Saharan African countries included in this analysis were countries that had the lowest human development indices in addition to having available datasets at the time of analysis. The Human Development Index (HDI) is a summary measurement on key dimensions of human development including life expectancy, knowledge, and standard of living [30]. The HDI ranks 188 countries with higher numerical rankings reflecting lower index scores and human development (Norway is number one, Niger is number 188). The countries with available datasets and the highest HDI rankings (lowest index scores) included the following DHS surveys: Democratic Republic of Congo 2013 (ranking 176), Mozambique 2003 (180), Sierra Leone 2013 (181), Guinea 2012 (182), Burkina Faso 2010 (183), and Burundi 2010 (184). These countries have both high gender inequality as well as low economic development. The discrepancies in the years of the surveys reflect variation in when the surveys were conducted and which questionnaire modules were included that year, as female healthcare decision-making sections are not included in every DHS round.

The DHS data sets are nationally representative surveys of women aged 15-49. Details regarding individual surveys are described in the final reports [31-36], but they use a multistage cluster design and were weighted to be nationally representative. Country-level sample sizes included Mozambique $(n=7,382)$, Burkina Faso ( $n$ $=13,797)$, Burundi $(n=5,124)$, Democratic Republic of Congo $(n=12,400)$, Guinea $(n=6,733)$, and Sierra Leone $(n=9,991)$. Wealth was measured in five distinct wealth quintiles: poorest, poorer, middle, richer, and richest. Each household was assigned a score for possession of assets from a standard list of easy-to-observe assets such as televisions, bicycles, type of flooring, etc. Asset scores were weighted and then were standardized in relation to normal distribution to define breakpoints for the five different quintiles. The construction of wealth quintiles has been described in prior literature [37].

Health care autonomy was measured using the DHS question: Who has the final say in health care decisions? Women had the following response options: respondent only, respondent and husband jointly, husband only, or someone else. Notably, there was significant missingness within the datasets which limits the analysis regarding this question. Missingness is reported as follows: Mozambique 0.2\%, Burkina Faso 19\%, Burundi $44 \%$, Democratic Republic of Congo 34\%, Guinea 26\%, and Sierra Leone $36 \%$. To assess the impact of wealth quintile on female healthcare autonomy for each country we calculated the relative risk ratio of a respondent versus her husband having the sole final say on her healthcare decisions between the richest and poorest wealth quintiles via a multivariate multinomial logistic regression model. We first tested bivariate associations of demographic factors identified in existing conceptual 
Table 1: Sample demographic characteristics by country.

\begin{tabular}{|c|c|c|c|c|c|c|}
\hline Characteristics & $\begin{array}{l}\text { Mozambique } \\
2003\end{array}$ & $\begin{array}{l}\text { Guinea } \\
2012\end{array}$ & $\begin{array}{l}\text { Burundi } \\
2010\end{array}$ & $\begin{array}{l}\text { Burkina } \\
\text { Faso } 2010\end{array}$ & $\begin{array}{l}\text { Sierra } \\
\text { Leone } 2013\end{array}$ & $\begin{array}{l}\text { Congo } \\
2013\end{array}$ \\
\hline Sample size & 7382 & 6733 & 5124 & 13797 & 9991 & 12400 \\
\hline \multicolumn{7}{|l|}{ Final say in health care (\%) } \\
\hline Respondent alone & $42.90 \%$ & $7.40 \%$ & $13.20 \%$ & $8.20 \%$ & $7.70 \%$ & $10.10 \%$ \\
\hline Respondent and husband & $13.30 \%$ & $26.30 \%$ & $64.70 \%$ & $16.30 \%$ & $47.30 \%$ & $36.40 \%$ \\
\hline Husband alone & $22.70 \%$ & $65.30 \%$ & $22.10 \%$ & $74.50 \%$ & $44.60 \%$ & $52.90 \%$ \\
\hline Someone else & $21.00 \%$ & $1.00 \%$ & $0.10 \%$ & $0.90 \%$ & $0.40 \%$ & $0.50 \%$ \\
\hline Wife beating justified for going out without permission & $35.20 \%$ & $82.90 \%$ & $47.00 \%$ & $29.60 \%$ & $54.00 \%$ & $48.90 \%$ \\
\hline Mean highest grade of education attained & 3.4 & 3.8 & 4.2 & 3.7 & 3.7 & 3.6 \\
\hline Mean number of children & 3 & 3 & 2.6 & 3.3 & 2.8 & 3.2 \\
\hline Mean age & 28.5 & 28.6 & 27.6 & 28.8 & 28.3 & 28.3 \\
\hline
\end{tabular}

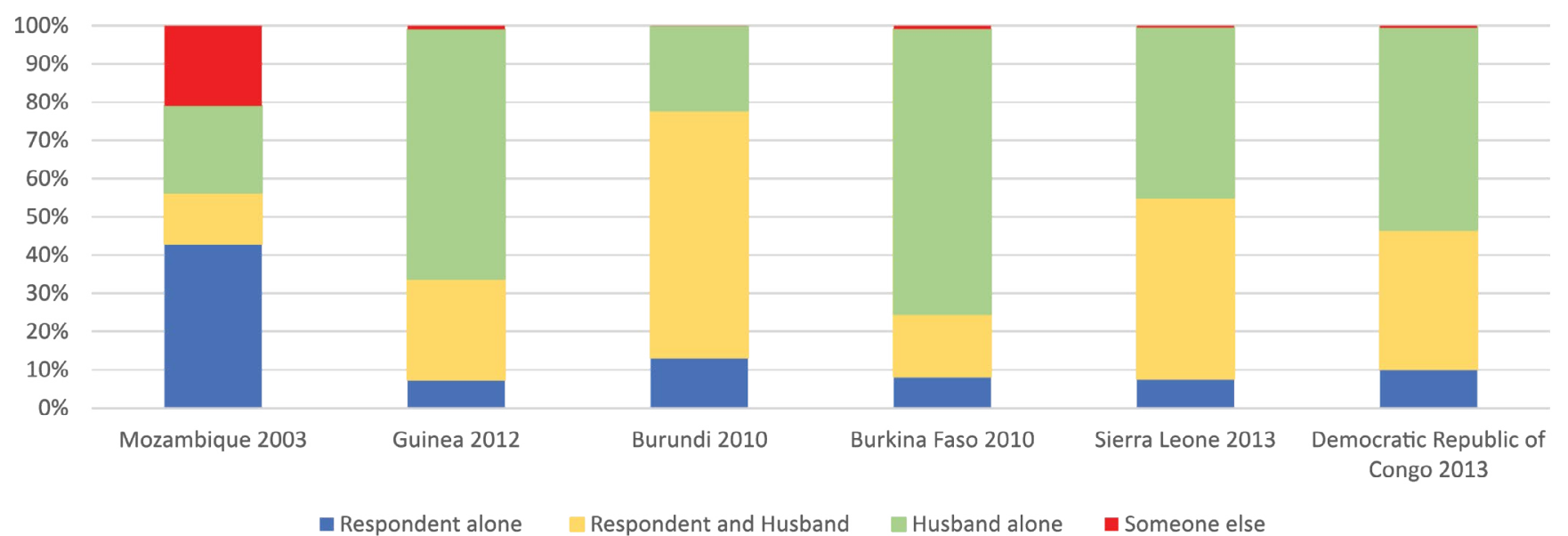

Figure 1: Healthcare decision-making distribution.

frameworks $[38,39]$ for statistically significant relationships to female healthcare autonomy. Education, age, and number of living children were all found to have significant associations ( $p<0.05)$ and prior literature has also supported their relationship with women's empowerment [40-42]. These factors were thus included as adjustment variables in the multivariate analysis. Another variable included was opinion on whether wife-beating is justified if a woman goes out without telling her husband. Given the high prevalence of domestic violence in these countries, this could be a major barrier to healthcare autonomy if a woman cannot leave her home out of fear. Unadjusted model results were also compared to the adjusted model.

Additional sensitivity analyses were performed to evaluate if joint (husband and respondent) decision-making was affected by wealth quintile. Accordingly, the relative risk ratio of a joint decision-making versus the husband alone determining health care decisions was calculated between the richest and poorest wealth quintiles. Effect modification between wealth and the adjustment variables was investigated in serial models and inclusion of these predictors were determined by Wald tests significant at a p-value of 0.05 . Data was analyzed using STATA Version 13.1 (Stata Corporation, College Station, TX). Using sample weights that adjusted for differences in probability of selection from survey design, characteristics from each country were described and the weighted distribution of the variables were assessed. Furthermore, all variance estimations were adjusted for complex survey design within the analyses.

\section{Results}

Sample demographic characteristics by country are presented in (Table 1). The mean age for all women in the study was 28.4 years. The average number of children was three and the average highest education level was grade 3.7. The mean age, number of children, and highest educational level attained did not vary significantly between countries. Large differences were observed in the opinion on whether wife-beating was justified for going out without permission. Less than a third (29.6\%) of women in Burkina Faso thought that it was justified compared to the majority of women in Guinea (82.9\%).

There were also significant variations in the distribution of healthcare decision-making between countries as demonstrated in (Figure 1). In Mozambique $43 \%$ of women reported that they made their healthcare decisions independently and $23 \%$ of women answered that their husbands alone made these decisions. Conversely, among Guinean women surveyed $7.4 \%$ made decisions alone, and $65 \%$ reported that their husbands alone made healthcare decisions for them. Mozambique was also unique in that $21 \%$ of women reported that "some- 


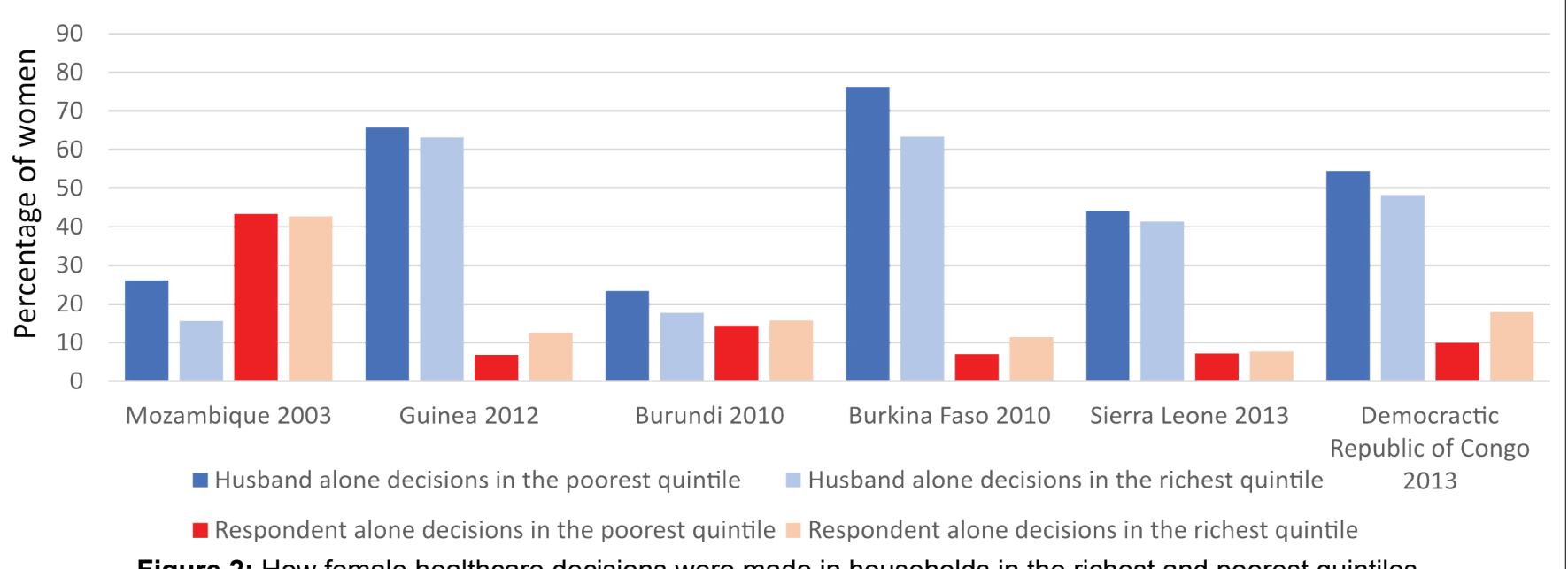

Figure 2: How female healthcare decisions were made in households in the richest and poorest quintiles.

Table 2: Unadjusted and adjusted relative risk ratios between richest and poorest quintiles.

\begin{tabular}{|c|c|c|c|c|c|c|}
\hline & $\begin{array}{l}\text { Mozambique } \\
2003\end{array}$ & $\begin{array}{l}\text { Guinea } \\
2012\end{array}$ & $\begin{array}{l}\text { Burundi } \\
2010\end{array}$ & $\begin{array}{l}\text { Burkina } \\
\text { Faso } 2010\end{array}$ & $\begin{array}{l}\text { Sierra } \\
\text { Leone } 2013\end{array}$ & $\begin{array}{l}\text { Congo } \\
2013\end{array}$ \\
\hline $\begin{array}{l}\text { Respondent vs. husband-only decision making } \\
\text { (unadjusted) }\end{array}$ & 1.65 & 1.93 & 1.42 & 1.97 & 1.17 & 2.03 \\
\hline $95 \%$ confidence interval & $1.39-1.97$ & $1.33-2.81$ & 1.02-1.99 & $1.53-2.54$ & $0.85-1.63$ & $1.64-2.51$ \\
\hline $\begin{array}{l}\text { Respondent vs. husband-only decision making } \\
\text { (adjusted) }\end{array}$ & 1.69 & 1.86 & 0.89 & 1.25 & 0.35 & 0.47 \\
\hline $95 \%$ confidence interval & $1.39-2.05$ & $1.22-2.83$ & $0.62-1.26$ & $0.92-1.70$ & $0.12-1.07$ & $0.07-2.95$ \\
\hline $\begin{array}{l}\text { Respondent and husband vs. husband-only } \\
\text { decision making (unadjusted) }\end{array}$ & 0.86 & 0.9 & 1.41 & 1.78 & 1.1 & 1.07 \\
\hline $95 \%$ confidence interval & $0.69-1.04$ & $0.68-1.20$ & $1.09-1.82$ & $1.45-2.19$ & $0.88-1.38$ & $0.88-1.31$ \\
\hline $\begin{array}{l}\text { Respondent and husband vs. husband-only } \\
\text { decision making (adjusted) }\end{array}$ & 0.86 & 0.84 & 1.02 & 1.2 & 0.47 & 0.43 \\
\hline $95 \%$ confidence interval & $0.69-1.08$ & $0.62-1.14$ & $0.78-1.34$ & $0.93-1.55$ & $0.62-1.14$ & $0.12-1.47$ \\
\hline
\end{tabular}

one else" made their healthcare decisions, a proportion that was $<1 \%$ in all of the other countries surveyed, and likely represents an elder household figure or parentin-law.

Differences in female and husband only decision-making between the richest and poorest wealth quintiles using predictions from the adjusted model and centered covariates are depicted in (Figure 2). A general trend of increased respondent only decision-making concomitant with decreased husband only decision-making between the richest and poorest quintiles was observed. Despite the suggestion of greater autonomy with greater wealth, the most prominent finding remained that respondent alone decision-making was overall low with gains of $<10 \%$ between the richest and poorest quintiles in all countries. Conversely the largest decrease in husband-only decision-making was seen in Burkina Faso between the richest and poorest quintile, and this also only reflected a $\sim 12.5 \%$ decrease. (Table 2) presents the unadjusted and adjusted Relative Risk Ratios (RRR) and 95\% Confidence Intervals (Cl) of respondent-only versus husband-only decision-making between the richest and poorest quintiles in the six countries. Prior to adjustment for age, education, number of children, and opinion on wife-beating, all coun- tries except for Sierra Leone demonstrated a statisticalIy significant greater likelihood of autonomy for women in the richest wealth quintile in comparison to the poorest (Relative Risk Ratios, RRR, 1.17-2.03). However, after adjustment only Mozambique and Guinea continued to have significant relationships between autonomous decision-making and wealth quintile. Figure 3 compares the relative risk ratios between countries in unadjusted and adjusted models.

Joint couple (husband and respondent) in comparison to husband-only decision-making relative risk ratios between the richest and poorest were statistically significant in the unadjusted analyses of Burkina Faso (RRR 1.97) and Burundi (RRR 1.42) only. These associations disappeared after covariate adjustment and are depicted in (Table 2). However, shared decision-making was overall common in many countries as demonstrated in (Figure 1). Guinea and Burkina Faso were the only countries where the majority of households reported husband-only decision-making.

\section{Discussion}

The determinants of female healthcare decision-making in low and middle income countries are multi factorial and complex. To our knowledge, this is the only study that 
Mozambique 2003 (unadjusted)

Mozambique 2003 (adjusted)

Guinea 2012 (unadjusted)

Guinea 2012 (adjusted)

Burundi 2010 (unadjusted)

Burundi 2010 (adjusted)

Burkina Faso 2010 (unadjusted)

Burkina Faso 2010 (adjusted)

Sierra Leone 2013 (unadjusted)

Sierra Leone 2013 (adjusted)

Congo 2013 (unadjusted)

Congo 2013 (adjusted)

\section{0}

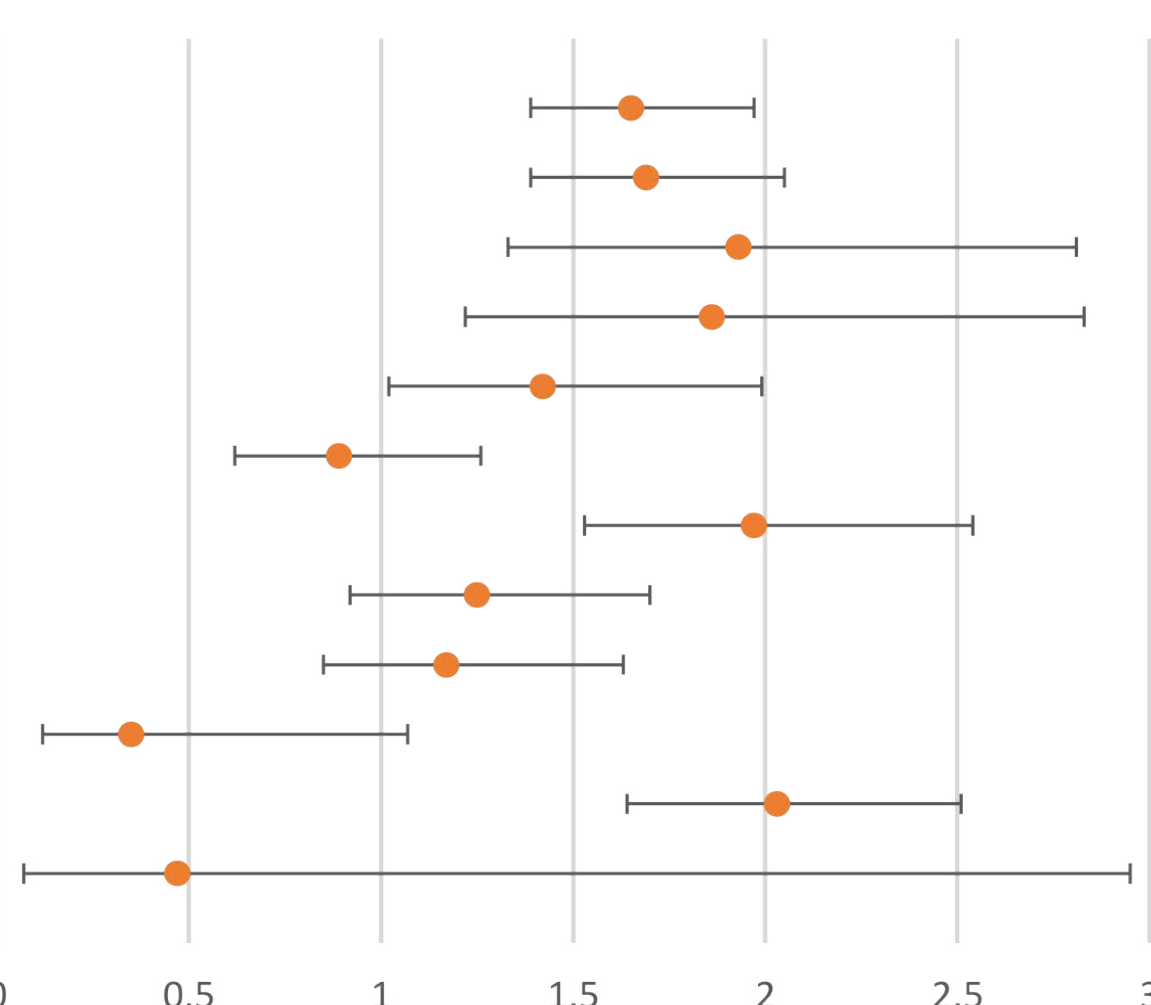

Figure 3: Relative risk ratio by countries. assesses female healthcare autonomy by wealth quintile in sub-Saharan Africa. Other studies have assessed composite measures of women empowerment in African countries that frequently include female healthcare autonomy, but it is worthwhile to look specifically at this factor as it is a key determinant in healthcare quality and outcomes. Additionally, in an era where unconditional cash transfers are becoming a popular mechanism of poverty reduction and foreign aid, it is useful to consider how wealth may be associated with health-seeking behaviors.

These surveys demonstrated that among the sub-Saharan countries with the lowest UN Human Development Index scores, there was great variability in women's healthcare decision-making. Although there is some evidence of a positive correlation between wealth quintile and female healthcare autonomy the link is not strong and country specific. Rather, the most consistent finding was that respondent-only decision-making was low among most countries outside of Mozambique and generally less than $20 \%$ of households. Mozambique was also unique in that $20 \%$ of respondents described "someone else" making healthcare decisions for them highlighting different cultural norms among nations. Studies in Bangladesh have reported that attitudes of inlaws and other family members have resulted in delays in mothers seeking postnatal care $[43,44]$. In particular, the role of purdah or the social and religious practice of female seclusion has been implicated as a barrier to healthcare in which a non-husband influence affects decisions. Women have reported feeling ashamed when being attended by a male health worker in many low and middle income countries [45-47].
Perhaps the most substantial finding of this analysis was the loss of correlative statistical significance between wealth and autonomy in many countries when controlling for the adjusted covariates of age, education, number of children, and opinion on wife-beating. Furthermore, between the richest and poorest wealth quintiles estimates of respondent-only and husband-only decision-making did not change significantly in absolute percentage values although they did generally follow a trend of increased autonomy with increased wealth. Prior literature has demonstrated a strong association for age and number of children with increased autonomy and influence [48-50]. Accordingly, when controlling for these factors it is not surprising that the correlation between wealth and autonomy was weakened and in many instances no longer significant. Age and number of children may well likely be more important than wealth for female healthcare autonomy. There are also many considerations such as religious affiliation, ethnicity, and cultural beliefs among others that could not be assessed in this study and have also been shown to affect healthcare decision-making [51-53].

As such, these findings contribute to existing literature by demonstrating empirical evidence of a weakly positive correlation between wealth status and women's healthcare empowerment. There remain many more questions to be investigated however. While paid employment is known to increase household autonomy it is unknown if these gains are also reflected in healthcare autonomy specifically, and if women in higher wealth quintiles also experience greater autonomy even without being independently employed. The non-finan- 
cial barriers for women in low and middle income countries may in fact pose more significant impediments to accessing healthcare and are both harder to measure and intervene upon. Qualitative studies also are still lacking in this area and needed to further elucidate the complex interplay of socio cultural and economic factors contributing to health seeking behaviors [51].

There are several limitations within this study. Most importantly this is a retrospective cross-sectional analysis and the relationship between wealth quintile and female healthcare autonomy is blurred by multiple confounders. It is not possible to assess a true counterfactual as in a randomized control trial. There may be distinct socioeconomic behavioral differences between families in lower versus higher wealth quintiles that affect female healthcare autonomy that have not been controlled for. Additionally, many of the countries had significant missingness that limit interpretation of data even with multiple imputation methods. Lastly, although presumably women are answering truthfully about decision-making patterns in their families, there are no existing validation studies to assess actual versus reported health-seeking behaviors in these women that these authors were able to find.

Despite significant limitations, this study offers some insight into the complex relationship between women's empowerment, healthcare access, and economic status. Given that gender equality, economic development, and improved healthcare represent core values of the millennium development goals, further research into this complex nexus is warranted to help develop future strategies that can benefit all three key components.

\section{Acknowledgments}

We are grateful to the DHS staff and teams that carried out and conducted these survey analyses in these countries and have made the data publicly available.

\section{Ethical Considerations}

Data collection was performed by the DHS staff which received training in ethics and confidentiality. Our team requested access to de-identified publicly available data for purposes of analysis and women's health research and followed DHS protocols.

\section{References}

1. (2015) Millennium Development Goals Report, United Nations.

2. Duflo E (2012) Women Empowerment and Economic Development. Journal of Economic Literature 50: 1051-1079.

3. Klasen S, Lamanna F (2009) The impact of gender inequality in education and employment on economic growth: New evidence for a panel of countries. Feminist Economics 15 91-132

4. Castle SE (1993) Intra-household differentials in women's status: household function and focus as determinants of children's illness management and care in Rural Mali. Health Transition Review 3: 137-157.

5. Gupta DM (1990) Death clustering mothers' education and the determinants of child mortality in Rural Pujab, India. Population Studies 44: 489-505.

6. Sen AK (1992) Missing women. BMJ 304: 586-587.

7. Klasen S, Wink C (2002) A turning-point in gender bias in mortality? An update on the number of missing women. Population and Development Review 28: 285-312.

8. (2016) United Nations Development Programme. Human Development Report 2016: Gender Inequality Index.

9. Brinda EM, Rajkumar AP, Enemark U (2015) Association between gender inequality index and child mortality rates: a cross-national study of 138 countries. BMC Public Health 15: 97.

10. Gakidou E, Cowling K, Lozano R, Murray CJ (2010) Increased Educational Attainment and its Effect on Child Mortality in 175 Countries between 1970 and 2009: A Systematic Analysis. Lancet 376: 959-974.

11. Jennings $L, N a M$, Cherewick M, Hindin M, Mullany B, et al. (2014) Women's empowerment and male involvement in antenatal care: analyses of Demographic and Health Surveys (DHS) in selected African countries. BMC Pregnancy Childbirth 14: 297.

12. Dyson T, Moore M (1983) On kinship structure, female autonomy, and demographic behavior in India. Population and Development Review 9: 35-60.

13. Abadian S (1996) Women's autonomy and its impact on fertility. World Development 24: 1793-1809.

14. Al Riyami A, Afifi M, Mabry RM (2004) Women's autonomy, education and employment in Oman and their influence on contraceptive use. Reprod Health Matters 12: 144-154.

15. Hogan DP, Berhanu B, Hailemariam A (1999) Household organization, women's autonomy and contraceptive behavior in Southern Ethiopia. Studies in Family Planning 30: 302-314.

16. Saleem S, Bobak M (2005) Women's autonomy, education and contraception use in Pakistan: a national study. Reprod Health 2: 8.

17. Adhikari R, Sawangdee Y (2011) Influence of women's autonomy on infant mortality in Nepal. Reprod Health 8: 7.

18. Ghuman SJ (2003) Women's autonomy and child survival: a comparison of Muslims and non-Muslims in four Asian countries. Demography 40: 419-436.

19. Shroff M, Griffiths P, Adair L, Suchindran C, Bentley M (2009) Maternal autonomy is inversely related to child stunting in Andhra Pradesh, India. Matern Child Nutr 5: 64-74.

20. Thomas D (1990) Intra-Household Resource Allocation: An Inferential Approach. The Journal of Human Resources 25: 635-664.

21. Duraisamy $P$, Malathy $R$ (1991) Impact of public programs on fertility and gender specific investment in human capital of children in rural India: cross sectional and time series analyses. Res Popul Econ 7: 157-187.

22. Bruce J, Lloyd C, Leonard A, Engle PL, Duffy N (1995) Families in focus: New perspectives on mothers, fathers and children. The Population Council, New York, USA.

23. The World Bank (2012) World Development Report: Gender Equality and Development. 
24. Johnson FC, Rogers BL (1993) Children's nutritional status in female-headed households in the Dominican Republic. Social Science and Medicine 37: 1293-1301.

25. Malhotra A, Schuler S, Boender C (2002) Measuring Women's Empowerment as a Variable in International Development. Gender and Development Group, World Bank.

26. Say L, Raine R (2007) A systematic review of inequalities in the use of maternal health care in developing countries: examining the scale of the problem and the importance of context. Bull World Health Organ 85: 812-819.

27. Acharya DR, Bell JS, Simkhada P, Van Teijlingen ER, Regmi PR (2010) Women's autonomy in household decision-making: a demographic study in Nepal. Reprod Health 7: 15 .

28. Nigatu D, Gebremariam A, Abera M, Setegn T, Deribe $K$ (2014) Factors associated with women's autonomy regarding maternal and child health care utilization in Bale Zone: a community based cross-sectional study. BMC Womens Health 14: 79.

29. Hanlon J, Barrientos A, Hulme D (2010) Just Give Money to the Poor: The Development Revolution from the Global South. Kumarian Press, Sterling, VA, USA.

30. United Nations Development Programme (2014) Human development report 2014: Sustaining human progress: Reducing vulnerabilities and building resilience.

31. Ministère du Plan et Suivi de la Miseenœuvre de la Révolution de la Modernité - MPSMRM/Congo, Ministère de la Santé Publique-MSP/Congo, ICF International (2014) République Démocratique du Congo Enquête Démographique et de Santé (EDS-RDC) 2013-2014. MPSMRM, MSP, and ICF International. Rockville, Maryland, USA.

32. Instituto Nacional de Estatística/Moçambique, Ministério da Saúde/Moçambique, and MEASURE DHS+/ORC Macro. Moçambique Inquérito Demográfico e de Saúde 2003-2005. Instituto Nacional de Estatística/Moçambique, Ministério da Saúde/Moçambique, and MEASURE DHS+l ORC Macro. Calverton, Maryland, USA.

33. (2013) Sierra Leone Demographic and Health Survey 2014 Statistics Sierra Leone - SSL and ICF International, SSL and ICF International. Freetown, Sierra Leone, Rockville, Maryland, USA.

34. (2013) Guinée Enquête Démographique et de Santé et à Indicateurs Multiples (EDS-MICS 2012). Institut National de la Statistique/Guinée and ICF International, Institut National de la Statistique/Guinée and ICF International. Rockville, Maryland, USA.

35. (2012) Enquête Démographique et de Santé et à Indicateurs Multiples (EDSBF-MICS IV) 2010. Institut National de la Statistique et de la Démographie - INSD/Burkina Faso and ICF International. Burkina Faso, Calverton, Maryland, USA.

36. (2012) Institut de Statistiques et d'ÉtudesÉconomiques du Burundi - ISTEEBU, Ministère de la Santé Publique et de la Luttecontre le Sida -MSPLS - Burundi, and ICF International. Burundi EnquêteDémographique et de Santé 2010. ISTEEBU, MSPLS, and ICF International. Bujumbura, Burundi.

37. Rutsein S, Johnson K (2004) The DHS Wealth Index. Measure DHS + ORC Macro. Calverton, Maryland, USA.

38. Mosedale S (2005) Assessing women's empowerment: towards a conceptual framework. Journal of International Development 17: 243-257.
39. Wado Yohannes Dibaba (2013) Women's autonomy and reproductive healthcare-seeking behavior in Ethiopia. ICF International DHS Working Papers No. 91. Calverton, Maryland, USA.

40. Mullany B, Hindin M, Becker S (2005) Can women's autonomy impede male involvement in pregnancy health in Katmandu, Nepal? Soc Sci Med 61: 1993-2006.

41. Thapa D, Niehof A (2013) Women's autonomy and husband's involvement in maternal care in Nepal. Soc Sci Med 93: 1-10.

42. Wodemicael G (2010) Do women with higher autonomy seek more maternal health care? Evidence from Eritrea and Ethiopia. Health Care Women Int.

43. Rashid SF, Hadi A, Afsana K, Begum SA (2001) Acute respiratory infections in rural Bangladesh: cultural understandings, practices and the role of mothers and community health volunteers. Trop Med Int Health 6: 249-255.

44. Barnett S, Azad K, Barua S, Mridha M, Abrar M, et al. (2006) Maternal and newborn-care practices during pregnancy, childbirth, and the postnatal period: a comparison in three rural districts in Bangladesh. $\mathrm{J}$ Health Popul Nutr 24: 394-402.

45. Kalim N, Anwar I, Khan J, Blum LS, Moran AC, et al. (2009) Postpartum haemorrhage and eclampsia: differences in knowledge and care-seeking behaviour in Two districts of Bangladesh. J Health Popul Nutr 27: 156-169.

46. Syed U, Khadka N, Khan A, Wall S (2008) Care-seeking practices in South Asia: using formative research to design program interventions to save newborn lives. J Perinatol 28: S9-S13.

47. Van Vo T, Hoat LN, Jan van Schie T (2004) Situation of the Kinh poor and minority women and their use of the maternal care and family planning service in Nam Dong mountainous district, Thuathien-Hue province, Vietnam. Rural Remote Heal 4: 255.

48. Klingberg-Allvin $M$, Binh $N$, Johansson A, Berggren $V$ (2008) One foot Wet and One foot Dry: transition into motherhood among married adolescent women in rural Vietnam. Journal of Transcultural Nursing 19: 338-346.

49. Duong DV, Binns CW, Lee AH (2004) Utilization of delivery services at the primary health care level in rural Vietnam. Soc Sci Med 59: 2585-2595.

50. Mills S, Bertrand JT (2005) Use of health professionals for obstetric care in northern Ghana. Stud Fam Plann 36: 4556.

51. O'Connell TS, Bedford KJ, Thiede M, Mclntyre D (2015) Synthesizing qualitative and quantitative evidence on non-financial access barriers: implications for assessment at the district level. Int J Equity Health 14: 54.

52. Young JT, Menken J, Williams J, Khan N, Kuhn RS (2006) Who receives healthcare? Age and sex differentials in adult use of healthcare services in rural Bangladesh. World Health Popul 8: 83-100.

53. Rahman M, Nakamura K, Seino K, Kizuki M (2012) Intimate partner violence and use of reproductive health services among married women: evidence from a national Bangladeshi sample. BMC Public Health 12: 913.

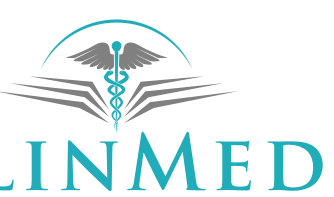

INTERNATIONAL LIBRARY 